\title{
Group plus individual education improved quality of life and lung function in patients with asthma
}

\author{
Gallefoss F, Bakke PS, Kjersgaard P. Quality of life assessment after patient education in a randomized controlled study on asthma \\ and chronic obstructive pulmonary disease. Am J Respir Crit Care Med 1999 Mar;159:812-7.
}

\section{Question}

Does an education programme improve health related quality of life and lung function in patients with mild to moderate asthma or chronic obstructive pulmonary disease (COPD)?

\section{Design}

Randomised, single blind (blinded assessment of spirometry results), controlled trial with follow up at 12 months.

\section{Setting}

An outpatient chest clinic at a hospital in Norway.

\section{Patients}

140 consecutive patients (mean age $49 \mathrm{y}, 61 \%$ women) with bronchial asthma or COPD who were 18-70 years of age and did not have unstable ischaemic heart disease, heart failure, serious hypertension, diabetes mellitus, or kidney or liver failure. Patients with asthma had to have $\geq 80 \%$ of predicted forced expiratory volume at 1 second $\left(\mathrm{FEV}_{1}\right)$ in stable phase and 1 of a positive reversibility test, documented $20 \%$ spontaneous variability (peak expiratory flow and $\mathrm{FEV}_{1}$ ), or a positive metacholine test. Patients with COPD had to have $\geq 40 \%$ and $<80 \%$ of predicted $\mathrm{FEV}_{1}$. Follow up was $89 \%$.

\section{Intervention}

39 patients with asthma and 31 patients with COPD were allocated to receive the intervention; 39 patients with asthma and 31 patients with COPD were allocated to the control group. Separate sessions were held for patients with asthma and those with COPD. The intervention consisted of two 2 hour group sessions and 1-2 40 minute individual sessions with a nurse and 1-2 40 minute individual sessions with a physiotherapist. Group session 1 was led by a physician, who discussed self care, basic physiology, and prevention of attacks; group session 2 was led by a pharmacist who addressed asthma drugs; in the individual sessions, a nurse focused on self care and a physiotherapist addressed topics such as respiration during exacerbations, pursed lip breathing, rest positions, and relaxation exercises. These sessions focused on establishing a partnership with the patient and repeating the essentials of the group sessions with a more individualised approach; individualised care plans were given to patients at the final session. Patients in the control group received usual care from their general practitioner.

\section{Main outcome measures}

Health related quality of life as assessed by the St George's Respiratory Questionnaire (SGRQ) (76 items, weighted to produce component scores for symptoms, activity, and impact, and a total score of overall respiratory health) and $\mathrm{FEV}_{1}$ assessed using spirometry.

\section{Main results}

At 1 year, patients with asthma who received the intervention had better health related quality of life (mean 16.3 unit difference in SGRQ scores, $\mathrm{p}<0.001$ ) and a higher mean $\mathrm{FEV}_{1}$ (increase of $3.4 \% v$ decrease of $2.7 \%, \mathrm{p}<0.05$ ) than patients in the control group. For patients with COPD, the intervention and control groups did not differ for health related quality of life or $\mathrm{FEV}_{1}$.

\section{Conclusion}

An education programme that included both group and individual sessions improved health related quality of life and lung function in patients with mild to moderate asthma but not in patients with chronic obstructive pulmonary disease.

Source of funding: Norwegian Medical Association.

For correspondence:Dr F Gallefoss, Section of Pulmonary Medicine, Medical Department, Vest-Agder Central Hospital, 4604 Kristiansand S, Norway.

\section{Commentary}

This study by Gallefoss $e t$ al supports the shift in thinking about the provision of patient education from a compliance model to one of self management for patients with chronic conditions, specifically asthma. Previous research has shown that self management education is effective in adults with asthma ${ }^{1}$ and other chronic conditions, such as arthritis. ${ }^{2}$

The lack of significant improvement in quality of life or lung function in patients with COPD is a quandary. Could the lack of effect be explained by the small sample size, or does the permanent nature of this disease affect its responsiveness to prevention and treatment strategies? Because the authors did not describe the extent of patient involvement in the design of the programme, it is unclear whether the education programme met the needs of patients with COPD.

The major message of this study is that self management can promote positive health outcomes. We need to determine how it can work with specific patient populations. For example, a combination of education and rehabilitation strategies may be more effective for patients with COPD. The results are relevant to interdisciplinary teams caring for patients with asthma and other chronic conditions and their families. This study emphasises that education is more than just information about disease and treatment. The development of a partnership between clinician and patient to individualise the information provided in the group sessions is key to helping patients to become self managers.
This provides nurses with the opportunity to help patients to learn and practice skills for dealing with their illness, daily activities, and the changing emotions brought about by chronic illness. ${ }^{3}$

Theresa Harper, RN, MSN Lindsay Wizowski, RN, MEd Patient Education Specialists Hamilton Health Sciences Corporation Hamilton, Ontario, Canada

1 Gibson PG, Coughlan J, Abramson H, et al. The effects of self-management education and regular practitioner review in adults with asthma. (Cochrane Review, latest version 26 Feb 1998). In: Cochrane Library: Update Software.

2 Lorig K, Holman H. Arthritis selfmanagement studies: a twelve-year review. Health Educ Q 1993;20:17-28.

3 Lorig K, Holman HR, Sobel D, et al. Living a healthy life with chronic conditions. Palo Alto,
California: Bull Publishing, 1994. 